\title{
O segredo de justiça e a publicidade dos atos processuais e administrativos no Código de Processo Civil
}

The secrecy of justice and the publicity of procedural and administrative acts in the Code of Civil Procedure

El secreto de justicia y la publicidad de actos procesales y administrativos en el Código de Procedimiento Civil

\section{Resumo}

O presente artigo objetiva demonstrar as exceções à regra da publicidade dos atos processuais e administrativos prevista no Código de Processo Civil. Para tanto, descreve as hipóteses em que poderá ser conferido o segredo de justiça a um processo, ressaltando que as hipóteses estão restritas ao rol taxativo previsto no Código de Processo Civil, bem como procede-se com a análise do direito fundamental à publicidade dos atos processuais e administrativos bem como a sua intrínseca relação com os direito ao acesso à justiça, ao contraditório e à ampla defesa, descrevendo que as hipóteses de segredo de justiça não constituem afronta à Constituição Federal, na medida em que igualmente objetivam resguardar determinadas situações relacionadas ao direito à intimidade e vida privada das partes, sendo a razão de ser do referido rol taxativo previsto no diploma processual civil. Logo, concluiu-se que valendo-se de critérios de ponderação e pela análise do caso concreto, nem a hipótese de segredo de justiça, nem a regra da publicidade dos atos, constituem violação de direitos. Optou-se pela metodologia dedutiva, com pesquisas bibliográficas em doutrina, Constituição Federal e em legislação infraconstitucional.

Palavras-chave: Publicidade; Segredo de justiça; Processo.

\begin{abstract}
This article aims to demonstrate the exceptions to the rule of publicity of procedural and administrative acts provided for in the Code of Civil Procedure. For this purpose, it describes the hypotheses in which the secrecy of justice may be conferred on a process, noting that the hypotheses are restricted to the exhaustive list provided for the Code of Civil Procedure, as well as the analysis of the fundamental right to publicity of procedural and administrative acts, as well as its intrinsic relation with the right to access to justice, the adversary system and full defense, describing that the hypotheses of secrecy of justice do not constitute an affront to the Federal Constitution, insofar as they also aim to protect certain situations related to the right to intimacy and private life of the parties, being the reason for the aforementioned exhaustive list provided for in the civil procedural diploma. Therefore, it was concluded that using weighting criteria and the analysis of the concrete case, neither the hypothesis of secrecy of justice, nor the rule of publicity of the acts, constitutes a violation of rights. We opted for the deductive methodology, with bibliographical research in doctrine, Federal Constitution and infra-constitutional legislation.
\end{abstract}

Keywords: Publicity; Secrecy of justice; Process.

\section{Resumen}

Este artículo tiene como objetivo demostrar las excepciones a la regla de publicidad de los actos procesales y administrativos previstas en el Código de Procedimiento Civil. Por tanto, describe las hipótesis en las que se puede conferir el secreto de justicia a un proceso, señalando que las hipótesis se limitan a la lista exhaustiva prevista en el Código de Procedimiento Civil, así como el análisis del derecho fundamental a la publicidad de los actos procesales y administrativos, así como su relación intrínseca con el derecho de acceso a la justicia, el sistema contradictorio y la defensa plena, describiendo que las hipótesis del secreto de justicia no constituyen una atentado a la Constitución Federal, en la medida en que también pretenden proteger determinadas situaciones relacionadas con el derecho a la intimidad y la vida privada de las partes, siendo el motivo de la lista exhaustiva antes mencionada prevista en el diploma procesal civil. Por tanto, se concluyó que utilizando criterios de ponderación y el análisis del caso específico, ni la hipótesis del secreto de justicia, ni la regla de publicidad de los hechos, constituyen una violación de derechos. Se optó 
por la metodología deductiva, con investigación bibliográfica en doctrina, Constitución Federal y legislación infraconstitucional.

Palabras clave: Publicidad; Secreto de justicia; Proceso.

\section{Introdução}

Primeiramente será abordado no presente trabalho a importância da publicidade dos atos processuais, publicidade essa que abrange também os atos administrativos, de modo a demonstrar a sua forte disposição na Constituição Federal.

Posteriormente será abrangido o segredo de justiça como uma exceção o princípio da publicidade dos atos processuais, de modo que será analisado como essa disposição projeta no Código de Processo Civil de 2015, o qual abarca um rol de incisos com as possibilidades, e será visto se trata-se de rol taxativo ou exemplificativo.

Por conseguinte, será analisado cada um dos incisos do art. 189, do referido diploma legal, no sentido de verificar acerca da aplicabilidade ou não do segredo de justiça no que concerne exclusivamente ao Processo Civil em nosso ordenamento jurídico, de modo que possa ser esclarecida a importância tanto da questão da publicidade dos atos processuais enquanto regra geral, e também do segredo de justiça, uma vez que a publicidade dos atos processuais não é regra absoluta e em alguns casos determinados há de se estabelecer o segredo de justiça com o objetivo de se resguardar certos direitos fundamentais que dentro do caso concreto são tidos como de maior importância em relação à publicidade, a exemplo da intimidade das pessoas e dentre outras questões.

\section{Metodologia}

Para o artigo em comento optou-se pela método hipotético-dedutivo, sendo a metodologia classificada quanto aos objetivos, em pesquisa exploratória, e quanto aos procedimentos, utilizou-se de pesquisa bibliográfica com base em entendimento doutrinário já produzido, com a apresentação de um raciocínio lógico extraído pela doutrina. Assim, esclarece José Carlos Köche (2011), que a pesquisa bibliográfica é imprescindível para que se possa realizar tanto a pesquisa descritiva quanto a experimental. Ademais, o autor também afirma que numa pesquisa é de suma importância que se realize uma análise teórica antecedente de forma a poder desenvolver os outros tipos de pesquisa, sendo que na pesquisa exploratória se trabalha com o levantamento da presença das variáveis e de sua configuração como sendo quantitativa ou qualitativa, e não com a relação entre essas variáveis.

Logo, verifica-se que a pesquisa em comento é qualitativa, pois conforme Gerhardt e Silveira (2009, p. 31), “a pesquisa qualitativa não se preocupa com representatividade numérica, mas, sim, com o aprofundamento da compreensão de um grupo social, de uma organização, etc.”, assim, a metodologia com suporte em pesquisa bibliográfica foi imprescindível para que se chegasse a um raciocínio lógico com as premissas estabelecidas na análise teórica, sobretudo em razão de se almejar com a presente pesquisa a demonstração da real necessidade de proteção à garantia constitucional da defesa dos atos processuais e administrativos.

\section{Resultados e Discussão}

\subsection{A publicidade dos atos processuais na Constituição Federal}

A publicidade dos atos processuais e administrativos trata-se de uma garantia fundamental pautada na justiça para que toda e qualquer pessoa possa ter acesso a informações no que concerne a todos os atos do processo, sendo que essa garantia encontra amparo legal na Constituição Federal de 1988 em seus artigos 5², LX e 93, IX, os quais dispõem respectivamente que: “a lei só poderá restringir a publicidade dos atos processuais quando a defesa da intimidade ou o interesse social o exigirem” e “todos os julgamentos dos órgãos do Poder Judiciário serão públicos, e fundamentadas todas as decisões, sob pena de nulidade, 
podendo a lei limitar a presença, em determinados atos, às próprias partes e a seus advogados, ou somente a estes, em casos nos quais a preservação do direito à intimidade do interessado no sigilo não prejudique o interesse público à informação".

Na mesma linha de entendimento, Gilmar Mendes (2021, p. 229) expõe que para que sejam efetivadas as garantias constitucionais de ampla defesa, contraditório e do devido processo legal, é imperioso que o processo seja guiado sob o controle da sociedade, ou seja, que o processo possa ser conduzido sob o controle das partes e da opinião pública, sem que haja nada a se camuflar.

Pode ser considerado, ainda que a publicidade do ato processual se trata de uma garantia política do exercício da função jurisdicional, na concepção de exercício de controle sobre ela, ou seja, na concepção de Estado de Direito (Bueno, 2016).

Assim, compreende-se que é indubitável o fato de a regra constitucional ser embasada na publicidade dos atos processuais, sendo o segredo de justiça uma exceção à regra geral, uma vez que apenas tratando-se de casos muito específicos e pontuais é que o processo será conduzido sob segredo de justiça (Gomes Júnior. Ferreira, 2015).

Por seu turno, Daniel Amorim Assumpção Neves (2016) explica e defende que:

No processo, a publicidade é, ao menos em regra, geral (qualquer sujeito tem acesso aos atos processuais) e imediata (facultada a presença de qualquer sujeito no momento da prática do ato processual). Daí por que qualquer sujeito, ainda que absolutamente desinteressado na demanda, pode assistir a uma audiência, a uma sessão de julgamento no tribunal ou analisar os autos do processo em cartório. No tocante aos julgamentos, poderá até assisti-los ao vivo pela TV Justiça a depender da repercussão do processo.

Ainda, o autor critica as restrições impostas pela limitação de livre acesso ao processo eletrônico a advogados devidamente cadastrados no Tribunal mesmo que não estejam vinculados ao processo, pois essa restrição acaba por violar o princípio da publicidade do processo, por impedir o acesso aos autos pelo público em geral.

Pelo exposto, a finalidade da publicidade dos atos processuais é assegurar a democracia, garantir que todo e qualquer cidadão possa ter acesso à justiça no sentido de poder verificar se o processo está sendo guiado dentro da legalidade, e, em contrapartida, é igualmente uma garantia à própria magistratura de que está exercendo a sua função com a devida ética, cuidado e zelo, de modo que possa demonstrar a todos que a justiça que está sendo exercida nada tem a esconder, ou seja, para que possa demonstrar transparência na condução processual.

Conforme esclarece Humberto Theodoro Júnior (2015, p. 167):

Explica-se a exigência constitucional pela circunstância de que na prestação jurisdicional há um interesse público maior do que o privado defendido pelas partes. Trata-se da garantia da paz e harmonia social, procurada por meio da manutenção da ordem jurídica. Daí que todos, e não apenas os litigantes, têm direito de conhecer e acompanhar tudo o que se passa durante o processo. Aliás, a publicidade é exigência do Estado Democrático que não se limita aos atos do Judiciário, pois a Constituição a impõe como princípio fundamental da Administração Pública praticada na esfera de qualquer dos Poderes institucionais (CF, art. 37).

Nesse sentido, pela publicidade dos atos processuais evita-se muitos abusos e arbitrariedades, e ainda é possível que apenas parte do processo tramite em segredo de justiça, como no caso de um processo de execução em que foi juntado comprovantes de rendimentos da parte, assim como uma forma de segurança para se resguardar essa parte no processo, esses documentos comprobatórios de rendimentos podem ficar sob segredo de justiça, sem que seja necessário que todo o processo trâmite sob esta maneira, por tratar-se de execução, e portanto, não ofendendo direitos constitucionais das partes.

Consoante as palavras de Cassio Scarpinella Bueno (2016):

A publicidade, tal qual exigida constitucionalmente, tem sentido duplo. A primeira acepção é a de que o direito brasileiro não admite julgamentos "secretos". Assim, todo o atuar do Estado-juiz é público no sentido de ser possível o acesso imediato a ele. A segunda é no sentido de que todas as decisões, para serem entendidas como tais, devem ser publicadas, isto é, tornadas públicas, acessíveis ao público em geral, Tudo o que caracteriza o "processo"- e "processo" sempre é 
bom lembrar, é o próprio método de atuação do Estado - é público, e, como tal, tem que estar disponível para quem quer que seja.

Desta forma, pode ser entendido que a publicidade dos atos processuais é um direito fundamental, uma garantia dentro de um Estado Democrático de Direito.

\subsection{O segredo de justiça no atual Código de Processo Civil}

Em que pese a publicidade dos atos processuais encontre amparo constitucional, o Código de Processo Civil estabelece uma lista de situações em que o processo poderá ser guiado sob segredo de justiça, sendo certo que tal previsão encontra amparo no artigo 189, I a IV, CPC/2015, entretanto deve ser destacado que o mencionado princípio trata-se de um rol exemplificativo (Araújo; Freitas, 2017), e isso porque conforme cada conjuntura, o juiz pode determinar o segredo de justiça para outros casos que não estão previstos nesse artigo, a exemplo do que pode acontecer quando o processo conta com dados confidenciais estratégicos para uma determinada empresa e que não podem ser divulgados, no que concerne ao direito de concorrência.

Deve ser mencionado ainda que as limitações estabelecidas pela CF e pelo CPC/2015 não são oponíveis às partes e a seus procuradores, o que equivale a dizer que nos casos que tramitam em segredo de justiça, as partes e seus respectivos procuradores ainda assim terão acesso amplo ao processo.

No ordenamento jurídico vigente prevalece como regra a publicidade absoluta, também chamada de externa, enquanto as exceções são tidas como manifestação do regime de publicidade restrita ou interna (Medina, 2015).

Desse modo, torna-se imperioso um estudo breve, porém mais detalhado sobre os incisos I a IV do artigo citado, conforme será visto adiante.

\subsubsection{Processos nos quais o interesse público ou social exija o segredo de justiça}

Deve ser destacado que interesse público é diferente de interesse social, já que o interesse público é o comum a todos (FREITAS, 2015), como em casos de proteção ambiental, uma vez a que proteção ambiental é assunto de interesse geral, porém não são todas as ações sobre meio ambiente que ensejam a aplicação de segredo de justiça com fundamento nesse inciso, mas um processo que trate acerca da probabilidade de ocorrência de desastre ambiental pode tramitar em segredo de justiça como forma de se evitar pânico na população.

Ainda conforme Vladimir Passos de Freitas, o interesse social diz respeito a uma parte mais restrita e delimitada da sociedade e pode haver determinação para que tramite em segredo de justiça como forma de se manter a paz social numa situação, por exemplo, de demanda contra o Poder Público tratando de medidas adotadas para realizar assentamento da população de baixa renda.

Assim, nesta primeira disposição de inciso o segredo de justiça pode ser determinado ex officio pelo juiz, ou também mediante provocação das partes, sendo que a decisão judicial que decrete o segredo de justiça com fundamento no interesse público ou social deve ser sempre motivada com a indicação precisa da questão que a justifique, ou seja, não é suficiente que o juiz mencione na decisão o interesse público ou social, é necessário que ele descreva qual seria o interesse público ou social em comento, sob pena de nulidade.

\subsubsection{Processos relacionados ao direito de família}

As situações familiares são questões que muitas vezes envolvem sentimentos, relacionamentos repletos de complexidade e tudo isso gera uma carga emocional muito grande para as partes envolvidas e às vezes atinge até mesmo os operadores do direito que trabalham na questão processual. 
Dessa maneira, o art. 189, II, CPC/2015 estabelece que devem tramitar em segredo de justiça os processos que versem sobre casamento, separação de corpos, divórcio, separação, união estável, filiação, alimentos e guarda de crianças e adolescentes, já que tratam-se de questões íntimas e por isso, como forma de se evitar constrangimentos e exposição pública desnecessária, a lei impõe que o processo que envolva direito de família tramite em segredo de justiça, como forma de se resguardar a intimidade das pessoas e de suas entidades familiares.

Acerca desse inciso, deve ser destacado que, diferente do inciso I que trata de situações em que o interesse público ou social assim exija o segredo de justiça, quando trata- se de segredo de justiça para questões de direito de família dispensa-se a motivação da decisão, porque configura-se uma imposição legal.

\subsubsection{Casos em que constem dados protegidos pelo direito à intimidade}

Para além do direito de família há outras determinadas situações que quando expostas publicamente podem gerar às partes envolvidas sentimento de vergonha e embaraços. Desta maneira, como a intimidade, a honra e o nome da pessoa são constitucionalmente protegidos em nosso ordenamento jurídico, há a possibilidade de se decretar o segredo de justiça, por exemplo, em processos que tratem de exposição de fotos ou vídeos íntimos de alguém; processos que tratem de pessoas portadoras de alguma doença ou enfermidade que cause estigmas ou ainda quando é juntada ao processo a declaração de bens e rendimentos de uma das partes para que se comprove a sua capacidade econômica.

Os dados bancários e financeiros devem ficar restrito a cada interessado, não havendo necessidade de se expor o saldo bancário de uma pessoa para toda a sociedade, até por questões de segurança, razão pela qual é possível que o processo ou ainda partes do processo, tramitem sob segredo de justiça.

Consoante José Miguel Garcia Medina (2015), é importante analisar o caso concreto para que se possa aferir qual direito deve preponderar. Assim, não se deve imaginar que o direito à informação é superior ao direito à intimidade ou vice-versa, pois cada direito fundamental é dotado do mesmo valor, aduzindo o autor que a situação fática deve ser verificada para que se possa aferir o âmbito de proteção dos direitos fundamentais, sendo por vezes necessário até mesmo que haja o confronto entre determinados direitos fundamentais, sendo inapropriado, conforme o autor, o uso da expressão ponderação, pois o que acontece na prática é a acertada análise dos bens que necessitam de maior proteção na situação fática.

Dessa forma, podemos entender que os direitos fundamentais não são absolutos, no sentido de que cada caso deve ser analisado particularmente para que possa ser compreendido qual prevalece sobre o outro. Pode haver casos em que prepondera um direito em detrimento do outro consoante a situação fática. Sendo, além de um juízo de ponderação, uma verdadeira análise no caso concreto conforme suas demandas.

\subsubsection{Arbitragem}

Conforme o disposto no art. 189, IV, CPC/2015, pode haver a determinação judicial para que o processo tramite em segredo de justiça quando versar sobre arbitragem, inclusive sobre cumprimento de carta arbitral, desde que a confidencialidade estipulada na arbitragem seja comprovada perante o juízo.

Acontece que conforme essa interpretação (Araújo, 2016), o processo arbitral se tornaria parecido com o processo judicial, podendo qualquer terceiro vir a tomar conhecimento do que nele ocorre, a menos que se decrete o segredo de justiça.

Assim, havendo arbitragem e desde que contenha previsão na convenção acerca da confidencialidade o processo pode tramitar em segredo de justiça, sendo que essa disposição foi inserida também no art. 22-C, parágrafo único da Lei 9.307/1996, a qual trata da arbitragem. 


\section{Conclusão}

Diante do que foi analisado, pode ser assimilado que em nosso ordenamento jurídico a publicidade dos processos é a regra, enquanto que o segredo de justiça trata-se de uma exceção que com o advento do CPC 2015 teve suas possibilidades aumentadas, tornando o rol do art. 189/ CPC ainda mais aberto, o que corrobora a ideia de ser este um rol exemplificativo e não taxativo.

Ademais, pode ser entendido que o princípio publicidade dos atos processuais é fundamental para que a justiça seja transparente e para que o processo seja guiado dentro da legalidade, evitando-se arbitrariedades.

Nesse sentido, em que pese a publicidade dos atos processuais seja essencial dentro do estado democrático de direito, é igualmente importante que determinadas questões que envolvam interesse público, social ou ainda a intimidade das partes, sejam analisadas e que o juiz verifique a necessidade de se determinar o trâmite em segredo de justiça, com o objetivo de proteger bens ainda maiores do que o direito de cada cidadão de ter acesso aos processos, dessa forma, há de se avaliar cada caso de modo que se defina cada bem jurídico a ser protegido.

Ademais, as hipóteses de cabimento de segredo de justiça presentes no CPC/2015 não devem ser vistas como um obstáculo à democracia ou à transparência da justiça, pelo contrário, devem ser entendidas como meios garantidores de proteção a direitos constitucionais, pois é certo que há situações em que uma exposição pública pode gerar danos imensuráveis às partes e por vezes até mesmo para a sociedade como um todo, a exemplo do que acontece no exemplo de demanda acerca da possibilidade de ocorrência de dano ambiental de grandes proporções, ou ainda nos casos em que o interesse público exige o segredo de justiça para que um caso seja solucionado sem inferência de agentes externos.

Dessume-se que para estudos futuros é de especial relevância a pesquisa acerca do Inquérito das Fake News, o qual foi instaurado visando a apuração de ameaças e notícias falsas contra os ministros da Suprema Corte. E tramita em segredo de justiça, tornando-se uma exceção à regra da publicidade dos atos administrativos e processuais na medida em que nem ao menos os advogados das partes possuem acesso aos autos do referido inquérito. Assim, para uma pesquisa futura é importante a análise do referido inquérito à luz dos princípios constitucionais, sobretudo da legalidade, da publicidade e do acesso à justiça.

\section{Referências}

Araujo, D. A. \& Freitas, E. P. M (2017). Segredo de justiça e princípio da publicidade dos atos processuais: uma análise acerca das inovações trazidas pelo novo código de processo civil. In. CONPEDI, XXVI, 2017, São Luiz - MA. Anais Processo Jurisdição e efetividade da justiça III: Maranhão, Brasil. p. 136 http://conpedi.danilolr.info/publicacoes/27ixgmd9/6hak5yqx/MDHM 2396i67zMJ31.pdf

Araujo, F. C. (2016). Curso de processo civil: parte geral. Atualizado com a Lei 13.256/2016. Malheiros.

Araujo N. P. I. M. (2016). A confidencialidade do procedimento arbitral e o princípio da publicidade. Revista de Informação Legislativa. RIl, 53(212). 139-154, https://www2.senado.leg.br/bdsf/item/id/528144.

Bonavides, P. (2012). Curso de direito constitucional. (27a ed.), Malheiros.

Branco, P. G. G \& Mendes, G. F (2020). Curso de direito constitucional. (15a ed.), Saraiva jur.

Bulos, U. L. (2012). Curso de direito constitucional. (7a ed.), Saraiva.

Brasil. (2015). Lei $n^{o}$. 13.105, de 16 de março de 2015: Código de processo civil. Brasília, DF

Brasil. (1988). Constituição Federal. Constituição da República Federativa do Brasil. Brasília, DF.

Bueno, C. S. (2016). Manual de direito processual civil: inteiramente estruturado à luz do novo CPC, de acordo com a Lei n. 13.256, de 4-2-2016. 2a ed. rev., atual. e ampl. - São Paulo: Saraiva.

Canotilho, J. J. G. (1997). Direito constitucional e teoria da constituição. (4a ed.), Almedina.

Carnelutti. F. (2020). Como se faz um processo. (3a ed.), Edijur.

Di Pietro, M. S. Z. (2014). Direito administrativo. (27a ed.), Atlas.

Dinamarco, C. R. \& Lopes, B. V. C. (2016). Teoria geral do novo processo civil. Malheiros. 
Research, Society and Development, v. 10, n. 13, e426101321579, 2021

(CC BY 4.0) | ISSN 2525-3409 | DOI: http://dx.doi.org/10.33448/rsd-v10i13.21579

Donizetti, E. (2017). Novo código de processo civil comentado. (2a ed.), Atlas.

Freitas, V. P. (2015). Segredo de justiça ainda desperta dúvidas na sua aplicação. Revista Consultor Jurídico.

Jr., Didier, F. (2012). Curso de Direito Processual Civil: Introdução ao Direito Processual Civil e Processo de Conhecimento. (14a ed.), Ed. Juspodivm.

Gerhardt, T. E. \& Silveira, D. T. (2009). Métodos de pesquisa. ed. UFRGS.

Gomes, L. M. Jr. \& Ferreira, Jussara Suzi Assis Borges Nasser (2015). O segredo de justiça no novo código de processo civil: análise das principais inovações. Revista de Processo. v. 250.

Koche, J. C. (2011). Fundamentos de metodologia científica. Vozes.

Medina, J. M. G. (2015). Novo código de processo civil comentado. Revista dos Tribunais. (3a ed.).

Mendes, G. F. (2012). Direitos fundamentais e controle de constitucionalidade. (4a ed.), Saraiva.

Mouzalas, R. \& Neto, J. O. T. \& Madruga, E. (2016). Processo Civil Volume Único. (8a ed.), ed. JusPodivm.

Neves, D. A. A. (2016). Novo código de processo civil comentado artigo por artigo. ed. JusPodvm.

Silva, J. A (1990). Curso de Direito Constitucional Positivo. (6a ed.), Revista dos Tribunais.

Theodoro, Jr. H. (2015). Curso de Direito Processual Civil: Teoria geral do direito processual civil, processo de conhecimento e procedimento comum. (56a ed.), Forense. 